\title{
Severe Asthma: Moving from Phenotype to Endotype Classification with Updates on Treatment
}

\section{Carlos Noujeim and Pierre Bou-Khalil}

Division of Pulmonary and Critical Care, Department of Internal Medicine, American University of Beirut Medical Center, Lebanon

*Corresponding author: Khalil PB, Division of Pulmonary and Critical Care, Department of Internal Medicine, American University of Beirut Medical Center, Beirut 1107 2020, Lebanon, Tel: 961-1350000; E-mail: pb05@aub.edu.lb

Received date: October 28, 2016; Accepted date: November 15, 2016; Published date: November 23, 2016

Copyright: ( 2016 Noujeim C, et al. This is an open-access article distributed under the terms of the Creative Commons Attribution License, which permits unrestricted use, distribution and reproduction in any medium, provided the original author and source are credited.

\begin{abstract}
Asthma has classically been categorized into several phenotypes to address the complexities of this disease. However, phenotypes only cover the clinically relevant aspects of the disease, but do not address the relationship between the disease and its etiology and pathophysiology. This led to the development of the term "endotypes" which links key pathogenic mechanisms with asthma phenotypes, and ultimately leads to better selection of treatment resulting in improved response. Although the exact pathogenesis of asthma is still under investigation, targeted-therapy based on asthma phenotypes and endotypes has shown some success, and the future appears promising for patients suffering from severe asthma since treatment is being tailored according to individual biology. We review in this manuscript the best evidence and updates currently available in the classification and treatment recommendations for severe asthma.
\end{abstract}

Keywords: Severe asthma; Exacerbations; Endotype; Biomarker; Treatment

\section{Introduction}

Asthma is a chronic inflammatory disease of the lower airways accompanied with acute symptoms like cough, shortness of breath, and chest tightness, and in few instances, fatal or near-fatal exacerbations [1]. It is a global health problem affecting around 300 million people worldwide. Due to geographical diversity, there is significant heterogeneity within the population of patients with asthma-like symptoms [1,2]. This heterogeneity is recognized on many levels of disease including pathophysiological mechanisms, environmental exposures, age and comorbidities, response to therapy, asthma exacerbations and long-term disease morbidities [3].

A significant minority of asthmatic patients are diagnosed with severe asthma, characterized by having daily symptoms and recurrent exacerbations despite compliance with high doses of inhaled steroids and other conventional medications [4]. It is important to identify these patients, properly diagnose them, and provide them with alternative or adjunctive therapies [5]. Many variables come into play in understanding asthma and it is important to comprehend the basic pathogenesis and merge it with the best clinical practice. Classifying patients based on baseline or static asthma severity score remains debatable. A recent trend has emerged to identify patients' disease according to phenotype which aids in both prognostication of exacerbation risk and providing endotype-specific treatment to minimize future exacerbations. This concise review aims to compile the best evidence and updates currently available in the classification and treatment recommendations for severe asthma.

\section{Definition of Severe Asthma}

Severe asthma is a broad term that encompasses formerly used terms such as difficult asthma, difficult-to-control asthma, brittle asthma, and refractory asthma [6]. It comprises 5-10\% of asthmatic patients, and consumes a significant percentage of the health care resources in Western countries $[7,8]$. Concepts of asthma severity are important in clinical evaluation of patients and also in assessing response to treatment. The World Health Organization (WHO) has specifically defined this population of patients in the following phrase: "Uncontrolled asthma which can result in risk of frequent severe exacerbations (or death) and/or adverse reactions to medications and/or chronic morbidity (including impaired lung function or reduced lung growth in children)" [9]. Under this definition of severe asthma, three subgroups of this family are recognized. These include untreated severe asthma, which is common in developing countries where access to therapy is limited and patients are often undertreated. The second subgroup is the difficult-to-treat asthma, in which patients have persistent uncontrolled asthma symptoms despite using inhaled controller therapy. These patients have increased exacerbation risks and significant comorbidities (like sinonasal disease, obesity, sleep apnea, gastroesophageal reflux disease, anxiety, and depression) [10]. The third class is treatment-resistant severe asthma, which is uncontrolled despite the use of highest level of recommended therapy. These patients suffer from persistent daily symptoms and recurrent and severe exacerbations [6].

The European Respiratory Society (ERS)/American Thoracic Society (ATS) Task Force on severe asthma reviewed the definition and provided recommendations and guidelines on the evaluation and treatment of severe asthma in children and adults [11]. When a diagnosis of asthma is confirmed and comorbidities have been addressed, severe asthma is defined as "asthma which requires treatment with high dose inhaled corticosteroids (ICS) plus a second controller (and/or systemic corticosteroids) to prevent it from becoming 'uncontrolled' or which remains 'uncontrolled' despite this therapy." Table 1 summarizes the recommended asthma treatment. A stepwise approach is usually advocated to assist, not replace, the clinical decision making required to meet individual patient needs. 
This approach requires that preferred treatment is used, when response to alternative is inadequate, before stepping up [11].

\begin{tabular}{|l|l|}
\hline Step/level & \\
\hline 1 & Preferred: SABA PRN \\
\hline 2 & Preferred: Iow dose ICS \\
\hline & Alternative: cromolyn, LTRA, nedocromil, or theophylline \\
\hline 3 & Preferred: low dose ICS+LABA or medium dose ICS \\
\hline 4 & Alternative: low dose ICS plus either LTRA, theophylline or zileuton \\
\hline & Preferred: medium dose ICS+LABA \\
\hline 5 & Alternative: medium dose ICS plus either LTRA, theophylline or zileuton \\
\hline 6 & Preferred: high dose ICS +LABA and consider omalizumab for patients who have allergies \\
\hline
\end{tabular}

Table 1: Stepwise approach in managing asthma in adolescents and adults, Abbreviations: SABA: Short-Acting Beta2-Agonist; ICS: Inhaled Corticosteroid; LTRA: Leukotriene Receptor Antagonist; LABA: Long-Acting Beta2-Agonist.

\section{Severe Asthma Phenotypes}

Generally, asthma is described based on phenotype, which is the expression of the patients' observable characteristics, manifested by the interaction between his/her genes (genotype) and the environment. These characteristics are divided into 2 categories: clinical phenotypes and inflammatory phenotypes (Table 2) [12,13]. The three most relevant clinical phenotypes are: (a) Frequent severe exacerbations with periods of relative stability between exacerbations (asthma with frequent severe exacerbations), (b) Irreversible airway obstruction (asthma with fixed airflow obstruction), and (c) Disease requiring systemic corticosteroids for its routine control (corticosteroiddependent asthma) [13]. Inflammatory sub-phenotypes are classified according to the predominant cells in sputum as eosinophilic ( $>3 \%$ eosinophils), neutrophilic ( $>61 \%$ neutrophils) and paucigranulocytic (both cells are within normal values) [14]. However, this phenotypic characterization is not static and may change over time in response to new environmental insults. Hence, it may be wrong to select a single dominant phenotype for each individual as it often leads to an inherent bias by ignoring the overlap between different groups.

\begin{tabular}{|ll|}
\hline \multicolumn{1}{|c|}{ Clinical phenotypes } \\
\hline$\cdot$ & Asthma with frequent severe exacerbations \\
\hline$\cdot$ & Asthma with fixed airflow obstruction \\
\hline$\cdot \quad$ & Corticosteroid-dependent asthma \\
\hline & $\quad$ Inflammatory phenotypes \\
\hline$\cdot$ & Persistent severe eosinophilic asthma \\
\hline$\cdot \quad$ & Non-eosinophilic severe asthma with increased neutrophils \\
\hline$\cdot$ & Severe paucigranulocytic asthma \\
\hline
\end{tabular}

Table 2: Phenotypes of severe asthma.

\section{Endotypes: New Asthma Classification}

Asthma has always been described in terms of its different phenotypes, without these being related to the underlying disease mechanisms. The pathogenetic mechanisms described in asthma include allergic and eosinophilic inflammation, neuro-immune interaction, airway hypersensitivity, bronchial remodeling, steroid resistance and decreased response to other therapies [15]. The heterogeneity observed in asthma demands a non-uniform treatment approach, and treating asthma based on phenotype alone is suboptimal, given the variability in treatment response [16]. To address such constraints, researchers are validating the term endotype as a link between a certain phenotype and the underlying pathogenetic mechanisms. Endotypes refer to subpopulations of a disease with similar molecular mechanisms or treatment responses and this approach, when combined with phenotypes, elicited more effective treatment responses $[16,17]$. It is believed that phenotypic clusters of diseases may come out from a specific endotype. Such asthma classification based on phenotypes and endotypes also provides advantages for genetic, epidemiological and medication-related longitudinal studies $[15,18]$.

In order to differentiate between asthma endotypes, 7 different parameters have been identified as clinically relevant: clinical characteristics, biomarkers, lung physiology, genetics, histopathology, epidemiology, and treatment response. There characteristics have been recorded in the PRACTALL consensus (PRACTical ALLergy), which includes experts from the European Academy of Allergy and Clinical Immunology and the American Academy of Allergy Asthma and Immunology [18]. Six endotypes meeting at least 5 of the proposed 7 parameters have been recognized. Wenzel recently proposed another classification of 5 asthma endotypes [19]. The different endotypes are summarized in Table 3 . The description of these endotypes was also discussed by others $[18,19]$. 
Page 3 of 7

\begin{tabular}{|l|l|}
\hline \multicolumn{1}{|c|}{ PRACTALL Consensus classification [16] } & \multicolumn{1}{|c|}{ Wenzel classification [17] } \\
\hline$\cdot \quad$ Aspirin-sensitive asthma & $\cdot$ Early-onset allergic asthma \\
\hline$\cdot \quad$ Adult allergic asthma & $\cdot$ Persistent eosinophilic asthma \\
\hline$\cdot \quad$ Allergic bronchopulmonary mycosis & $\cdot$ Allergic bronchopulmonary mycosis \\
\hline$\cdot \quad$ Severe late-onset hypereosinophilic asthma & $\cdot$ Obese female \\
\hline$\cdot \quad$ Preschoolers with wheezing and positive asthma predictive indices & $\cdot$ Neutrophilic asthma \\
\hline$\cdot \quad$ Asthma in cross-country skiers & \\
\hline
\end{tabular}

Table 3: Endotype of severe asthma.

\section{Asthma Endotypes and Biomarkers}

Detailed knowledge of the basic inflammatory patterns underlying bronchial asthma is fundamental. Figure 1 illustrates an overview of asthma pathophysiology. There is promising research involving biomarkers and cytokines that will better define the endotypes of asthma, which will certainly lead to better asthma control.

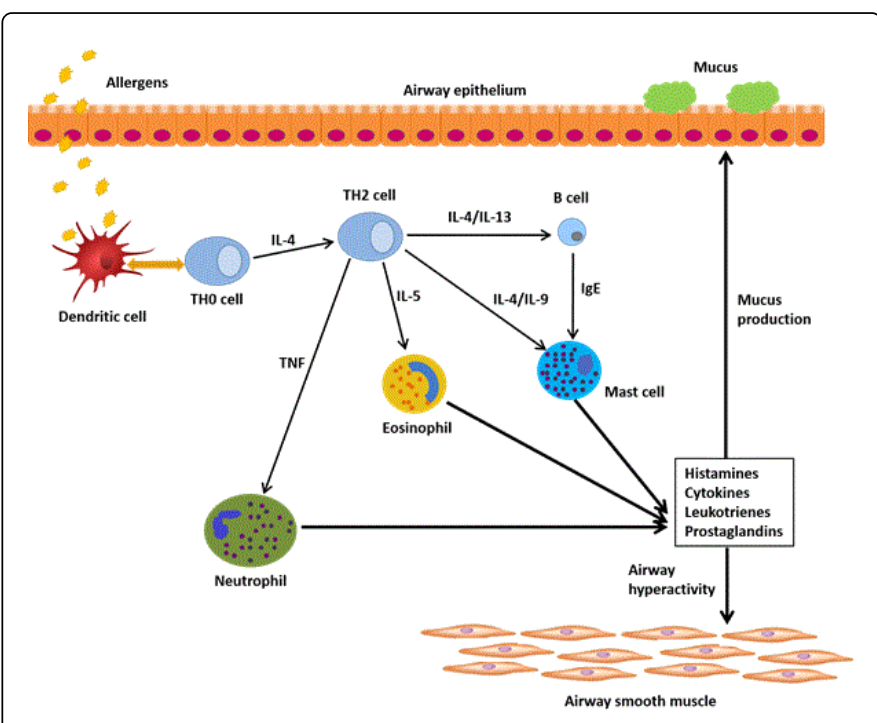

Figure 1: Overview of asthma pathophysiology as illustrated by the interaction between different inflammatory cells and the external environment including allergens. Key players in this mechanism include the $\mathrm{T}$ helper type 2 (Th2) cells which secrete cytokines including IL-4, IL-5 and IL-13, that activate inflammatory cells such as eosinophils and mast cells. Ultimately, airway smooth muscle cells are activated and airway epithelial cells over-secrete mucus.

\section{Cytokines}

Out of many, T helper type 2 cells (Th2) and their related cytokines were discovered in blood or respiratory secretions, and in some bronchial-derived proteins and electronic breath prints. Such detection will set up grounds for a predictive assessment, targeted therapy and enhanced follow-up. A simple diagnostic test in evaluating asthmatic patients and stratifying them would be the identification of blood or sputum eosinophils, as it is usually an evidence of Th2-type inflammation in the lungs [20]. In this eosinophilic asthma phenotype, patients who have significant eosinophilia $(>150 / \mu \mathrm{L})$ or more than $25 \%$ in this study, will continue to have blood eosinophilia; a simple measurement considered as a reliable biomarker for this phenotype [21]. In addition, another study concluded that blood eosinophil counts and derived ratios (eosinophil/lymphocyte ratio and eosinophil/neutrophil ratio) can accurately predict eosinophilic asthma in patients with persistent uncontrolled asthma despite treatment [22].

In addition to IL-5 and IL-13, IL-17 is another cytokine known to play an important role in certain subgroups of asthma [23]. Izuhara et al. by cluster analysis, recognized a particular asthma phenotype that has a rapid FEV1 decline $\left(>30 \mathrm{ml} \mathrm{y}^{-1}\right)$ with low ACT (Asthma Control Test) and high serum IL-6. This group had a mixed component (eosinophilic and neutrophilic on cell blood count, $\geq 250$ eosinophil/ $\mu \mathrm{L}$ and $\geq 5000$ neutrophil/ $\mu \mathrm{L}$ ) [24]. On-going effort is made to enhance the existing cytokine inhibitors, and to develop new ones, which would be a valuable additional treatment in refractory, difficultto-treat asthma.

Epithelial cell-derived cytokines including thymic stromal lymphopoietin (TSLP), IL-25, and IL-33 are believed to potentiate the immune system in the presence of actual or perceived damage in asthma. AMG 157 is a human anti-TSLP monoclonal immunoglobulin that has been tried in a double-blind, placebo-controlled study enrolling patients with mild allergic asthma; AMG 157 showed a decrease in allergen-induced bronchoconstriction [25]. A monoclonal anti-IL-25 antibody in mice prevented airway hyper-responsiveness [26], which may be promising in asthma treatment. There is also evidence that anti-IL-33 reduces airway inflammation and remodeling in mice [27].

\section{Periostin}

Further biomarkers are being developed which accurately correlate with the underlying pathophysiology. Serum periostin is one of these markers that have been evaluated in reflecting the status of inflammation. In asthmatic subjects, it is overexpressed in the bronchial subepithelium and affects collagen in the extracellular matrix, consequently leading to subepithelial remodeling and fibrosis. Periostin serum levels are significantly increased in subjects with Th2 phenotype and probable excess IL-13 activity [28]. A vital role in airway remodeling is to be better identified. It is anticipated by experts that serum periostin will be applied to treatment of asthma [29]. 


\section{Exhaled NO and breathprints}

Analysis of exhaled breath condensate by nuclear magnetic resonance spectroscopy is a novel promising technique that helps identify advanced pathophysiological mechanisms, biomarkers and therapeutic targets [30]. Such futuristic technologies still lack convincing data, especially in severe asthmatics, and the best biomarker is yet to be determined. A more classic diagnostic technique currently available is exhaled nitric oxide (NO) measurement. NO is produced by all tissues in the body, including the respiratory system. The concerned enzyme is NO synthase, which is under the direct control of Th2 cytokine IL-13 [31]. Exhaled NO has been shown to correlate moderately with bronchial and blood eosinophilia in asthmatic patients [32]. Elevated concentrations of exhaled NO therefore reflect increased IL-13 activity, and indicate the presence of a Th2 phenotype. The determination of a Th2 or non-Th2 phenotype plays a central role in predicting therapy response. Blood eosinophilia and elevated NO levels suggest that patients will be more likely to respond to corticosteroids. It was found that patients with severe asthma, characterized by an elevated exhaled NO level and sputum eosinophils despite high-dose corticosteroid therapy; correspond to a steroid-insensitive subgroup (U-BIOPRED Asthma Cohort). Poor asthma control with a non-Th2 or non-eosinophilic phenotype poses an even greater challenge. In the presence of sputum neutrophilia, options may include chronic macrolide therapy [33]. This beneficial effect might be from macrolides' anti-inflammatory and immunomodulatory properties.

\section{Therapy of severe asthma}

\section{Biological treatments}

Several molecules involved in the pathogenesis of asthma have been targeted as a treatment for severe asthma. Most are still in various phases of research, and currently only omalizumab is approved for use. Omalizumab is a humanized monoclonal antibody that can bind to free circulating IgE and consequently inhibits its binding to mast cells. This action reduces the release of mediators of allergic reactions. Omalizumab has been studied in patients with severe asthma, and it was shown that it is effective as a steroid-sparing drug and in decreasing the frequency of asthma exacerbations [34,35].

Mepolizumab, an IL-5 inhibitor, significantly reduced the number of asthma exacerbations [36], as well as sputum production, blood eosinophil counts, the number of prednisolone doses required in steroid-dependent subjects [37] and improved AQLQ (Asthma Quality of Life Questionnaire) scores [38]. A study by Bel et al. showed that mepolizumab had a significant glucocorticoid-sparing effect, reduced exacerbations, and improved control of asthma symptoms in patients requiring daily oral glucocorticoid therapy [39]. In severe eosinophilic asthma, mepolizumab, administered either intravenously or subcutaneously, significantly reduced asthma exacerbations and was associated with improvements in markers of asthma control [40]. Interestingly, mepolizumab did not show clinical benefit in mild-tomoderate asthmatic patients; only patients with severe asthma and persistent eosinophil expression had a reduction in their exacerbations $[41,42]$.

\section{Anticholinergics}

In refractory cases or with continuous usage of oral corticosteroids, severe asthmatics on standard combination therapy may benefit from adding tiotropium. Several years ago, Barnes et al. demonstrated that after prolonged LABA (long-acting beta agonists) stimulation, cholinergic transmission would be down-regulated. Nonetheless, this effect can be dampened by the concomitant usage of anticholinergic drugs [43]. Moreover, B2-adrenoreceptors are desensitized via the muscarinic M3 protein kinase C-mediated phosphorylation, and anticholinergic agents will protect against such heterologous desensitization [44]. Furthermore, tiotropium exhibited a possible anti-inflammatory effect, as shown by a limited reduction in exhaled NO [45]. A recent study illustrated that poorly controlled asthmatics on inhaled glucocorticoids and LABAs had modest sustained bronchodilation, and an increased time to first exacerbation episode with the addition of tiotropium [46]. This dual combination of LABA/ LAMA (long-acting muscarinic antagonists) does not clearly reveal the cardiovascular side effects, and its use in clinical practice is awaiting further large randomized studies.

\section{Macrolides}

Currently, the asthma treatment guidelines do not recommend antibiotics for the treatment of asthma if a bacterial infection is not confirmed. However, there is evidence that some patients with severe asthma are infected with atypical bacterial such as Chlamydia pneumonia and Mycoplasma pneumonia $[47,48]$. There is evidence to suggest that macrolides like clarithromycin target neutrophilic airway inflammation. A study of 45 refractory asthmatics showed that an 8 week course of clarithromycin at a dose of $500 \mathrm{mg}$ twice daily significantly reduced airway neutrophilia and sputum IL-8 and significantly improved AQLQ scores [49]. However, a Cochrane review concluded that there is not enough evidence to recommend using macrolides in patients with asthma [50]. Consequently, the role of macrolide antibiotics in patients with severe asthma remains controversial and future research is needed to verify its use.

\section{Immunotherapy}

In allergic asthma, subcutaneous immunotherapy is recommended as an adjunct to standard medications. However, since multiple triggers can induce asthma, cautious selection of patients is needed in order to gain maximum benefit. Objective outcomes were described in some studies, including improved symptoms and peak expiratory flow rate measurements when used in ragweed-induced asthma [51], reduced methacholine-induced hyperreactivity in patients allergic to grass pollen [52] and a reduction by half of fluticasone requirements in a 2 year study using dust mite allergoid preparation [53]. Despite its constraint to the allergic asthma phenotype, immunotherapy carries additional limitations. The sublingual form lacks consistent evidence in advanced asthmatic patients and overall home safety. In severe, highrisk asthmatics, including recent in-hospital care for exacerbation, those with an FEV1 less than $75 \%$ or on chronic oral steroid usage, such groups are at a higher risk for systemic allergic reactions or airways constriction and immunotherapy should be withdrawn [54]. It is recommended to initiate anti-IgE with an aggressive control by the standard therapy, then adding the immunotherapy for up to 3 to 5 years [55]. Also relevant data states that children will have a better profit in prevention of disease progression, as long-standing allergic asthma would respond less to immunotherapy [56].

\section{Anti-IL-4}

IL-4 is involved in asthma through many pathways such as IgE production, eosinophil chemotaxis, and production of IL-5 [57]. IL-4 
seems to be a rational target to control inflammation and reduce IL-5dependent pulmonary eosinophilia [58]. IL-4 inhibition was evaluated by Hart et al. using a pascolizumab which is a humanized anti-IL-4 monoclonal antibody [59]. Although the in vivo studies demonstrated a good tolerability of the drug, trials were aborted because pascolizumab did not significantly reduce circulating IgE [60].

Pitrakinra is an IL-4 variant that prevents binding of IL-4 and IL-13 to IL-4 alpha receptor. It was evaluated by inhalation in a double-blind trial in patients with moderate-to-severe asthma; however, it failed to demonstrate measurable clinical efficacy [61].

Dupilumab is another monoclonal antibody that blocks the alpha subunit of IL-4/IL-13 receptor. Wenzel et al. enrolled adult patients with moderate-to-severe asthma symptoms and high blood eosinophils or sputum eosinophil level in a double-blind placebo-controlled phase II clinical trial using dupilumab [62]. The number of asthma exacerbations was significantly lower in patients as compared to control. In addition, lung function was significantly improved as reflected in an increased FEV1.

\section{Anti-IL-13}

IL-13 displays an important role in Th2 inflammation, which makes it a potential target for therapy. Currently, there are three anti-IL-13 monoclonal antibodies under clinical evaluation: anrukinzumab, lebrikizumab and tralokinumab. Anrukinzumab is undergoing clinical trials and has been tested in asthma and ulcerative colitis in phase II studies [63]. Corren et al. conducted a randomized, double-blind, placebo-controlled study of lebrikizumab in asthmatic patients with uncontrolled disease [64]. Patients on lebrikizumab at a dose of 250 $\mathrm{mg} / \mathrm{month}$ for 6 months had a higher increase in FEV1 versus at baseline. Hanania et al. provided more evidence in support of lebrikizumab efficacy through two randomized, double-blind, placebocontrolled studies; they found that treatment with lebrikizumab reduced asthma exacerbations, in particular in periostin-high patients, with a significant $60 \%$ reduction, versus the subgroup of periostin-low patients [65]. However, the same group could not replicate these results in phase 3 trials and lebrikizumab did not consistently show significant reduction in asthma exacerbations in periostin-high patients [66]. Tralokinumab was tries in moderate-to-severe asthma patients with results in quality of life variation in subjects treated versus placebo [67]. Another randomized, double-blind, phase 2b study showed an acceptable safety profile for tralokinumab but a nonsignificant decline of asthma exacerbations [68].

\section{Ongoing Perspectives}

In order to practice better medicine, physicians must bear in mind the molecular/biological profile of each patient, and identify the interactions with the environment. Recent trends encourage moving from a simplified asthma diagnostic approach and classification towards a more complex phenotype and endotype-based strategies. However, organizing all the variables into new categories is very challenging. Scientists, researchers and pharmaceutical industries have combined their efforts in order to implement cross-sectional and longitudinal cohorts, with extensive testing and bio-banked samples, into an on-going U-BIOPRED asthma project consortium [69]. Such expertise is expected to improve diagnosis and therapeutic interventions mostly in difficult-to-treat asthmatics. Although the exact pathogenesis of asthma is still under investigation, targeting therapy based on asthma phenotypes and endotypes has shown some success, and the future appears promising for patients suffering from severe asthma since treatment is being tailored according to individual biology.

\section{Financial and Competing Interest's Disclosure}

The authors have no relevant affiliations or financial involvement with any organization or entity with a financial interest in or financial conflict with the subject matter or materials discussed in the manuscript. This includes employment, consultancies, honoraria, stock ownership or options, expert testimony, grants or patents received or pending or royalties.

No writing assistance was utilized in the production of this manuscript.

\section{References}

1. Killeen K, Skora E (2013) Pathophysiology, diagnosis and clinical assessment of asthma in the adult. Nurs Clin North Am 48: 11-23.

2. Bonfield TL, Ross KR (2012) Asthma heterogeneity and therapeutic options from the clinic to the bench. Curr Opin Allergy Clin Immunol 12: 60-67.

3. Wenzel SE (2006) Asthma: Defining of the persistent adult phenotypes. Lancet 368: 804-813.

4. Garcia G, Taillé C, Laveneziana P, Bourdin A, Chanez P, et al. (2013) Anti-interleukin-5 therapy in severe asthma. Eur Respir Rev 22: 251-257.

5. Ogawa Y, Calhoun WJ (2010) Phenotypic characterization of severe asthma. Curr Opin Pulm Med 16: 48-54.

6. McDonald VM, Gibson PG (2012) Exacerbations of severe asthma. Clin Exp Allergy 42: 670-677.

7. Braman SS (2006) The global burden of asthma. Chest 130: 4S-12S.

8. Moore WC, Bleecker ER, Curran-Everett D, Erzurum SC, Ameredes BT, et al. (2007) Characterization of the severe asthma phenotype by the National Heart, Lung and Blood Institute's Severe Asthma Research Program. J Allergy Clin Immunol 119: 405-413

9. Bousquet J, Mantzouranis E, Cruz AA, Ait-Khaled N, Baena-Cagnani CE, et al. (2010) Uniform definition of asthma severity, control and exacerbations: Document presented for the World Health Organization Consultation on Severe Asthma. J Allergy Clin Immunol 126: 926-938

10. Boulet LP (2009) Influence of comorbid conditions on asthma. Eur Respir J 33: 897-906.

11. Chung KF, Wenzel SE, Brozek JL, Bush A, Castro M, et al. (2014) International ERS/ATS guidelines on definition, evaluation and treatment of severe asthma. Eur Respir J 43: 343-373.

12. Campo P, Rodríguez F, Sánchez-García S, Barranco P, Quirce S, et al. (2013) Phenotypes and endotypes of uncontrolled severe asthma: new treatments. J Investig Allergol Clin Immunol 23: 76-88.

13. Bel EH, Sousa A, Fleming L, Bush A, Chung KF, et al. (2011) Diagnosis and definition of severe refractory asthma: An international consensus statement from the Innovative Medicine Initiative (IMI). Thorax 66: 910-917

14. Wang F, He XY, Baines KJ, Gunawardhana LP, Simpson JL, et al. (2011) Different inflammatory phenotypes in adults and children with acute asthma. Eur Respir J 38: 567-574.

15. Agache I, Akdis C, Jutel M, Virchow JC (2012) Untangling asthma phenotypes and endotypes. Allergy 67: 835-846.

16. Lin TY, Poon AH, Hamid Q (2013) Asthma phenotypes and endotypes. Curr Opin Pulm Med 19: 18-23.

17. Anderson GP (2008) Endotyping asthma: New insights into key pathogenic mechanisms in a complex, heterogeneous disease. Lancet 372: 1107-1119. 
18. Lötvall J, Akdis CA, Bacharier LB, Bjermer L, Casale TB, et al. (2011) Asthma endotypes: A new approach to classification of disease entities within the asthma syndrome. J Allergy Clin Immunol 127: 355-360.

19. Wenzel S (2012) Severe asthma: From characteristics to phenotypes to endotypes. Clin Exp Allergy 42: 650-658

20. Luzina IG, Lockatell V, Lavania S, Pickering EM, Kang PH, et al. (2012) Natural production and functional effects of alternatively spliced interleukin-4 protein in asthma. Cytokine 58: 20-26.

21. Katz LE, Gleich GJ, Hartley BF, Yancey SW, Ortega HG. (2014) Blood eosinophil count is a useful biomarker to identify patients with severe eosinophilic asthma. Ann Am Thorac Soc 11: 531-536

22. Zhang XY, Simpson JL, Powell H, Yang IA, Upham JW, et al. (2014) Full blood count parameters for the detection of asthma inflammatory phenotypes. Clin Exp Allergy 44: 1137-1145.

23. Petersen BC, Budelsky AL, Baptist AP, Schaller MA, Lukacs NW (2012) Interleukin-25 induces type 2 cytokine production in a steroid-resistant interleukin-17RB+myeloid population that exacerbates asthmatic pathology. Nat Med 18: 751-758

24. Izuhara Y, Matsumoto H, Kanemitsu Y, Izuhara K, Tohda Y, et al. (2014) GLCCI1 variant accelerates pulmonary function decline in patients with asthma receiving inhaled corticosteroids. Allergy 69: 668-673

25. Gauvreau GM, O'Byrne PM, Boulet LP, Wang Y, Cockcroft D, et al. (2014) Effects of an anti-TSLP antibody on allergen-induced asthmatic responses. N Engl J Med 370: 2102-2110.

26. Ballantyne SJ, Barlow JL, Jolin HE, Nath P, Williams AS, et al. (2007) Blocking IL-25 prevents airway hyper-responsiveness in allergic asthma. J Allergy Clin Immunol 120: 1324-1331.

27. Mizutani N, Nabe T, Yoshino S (2013) Interleukin-33 and alveolar macrophages contribute to the mechanisms underlying the exacerbation of IgE-mediated airway inflammation and remodelling in mice. Immunology 139: 205-218

28. Jia G, Erickson RW, Choy DF, Mosesova S, Wu LC, et al. (2012) Periostin is a systemic biomarker of eosinophilic airway inflammation in asthmatic patients. J Allergy Clin Immunol 130: 647-654.

29. Izuhara K, Ohta S, Ono J (2016) Using periostin as a biomarker in the treatment of asthma. Allergy Asthma Immunol Res 8: 491-498.

30. Ibrahim B, Marsden P, Smith JA, Custovic A, Nilsson M, et al. (2013) Breath metabolomic profiling by nuclear magnetic resonance spectroscopy in asthma. Allergy 68: 1050-1056

31. Chibana K, Trudeau JB, Mustovich AT, Hu H, Zhao J, et al. (2008) IL-13 induced increases in nitrite levels are primarily driven by increases in inducible nitric oxide synthase as compared with effects on arginases in human primary bronchial epithelial cells. Clin Exp Allergy 38: 936-946

32. van den Toorn LM, Overbeek SE, de Jongste JC, Leman K, Hoogsteden $\mathrm{HC}$, et al. (2001) Airway inflammation is present during clinical remission of atopic asthma. Am J Respir Crit Care Med 164: 2107-2113.

33. Brusselle GG, Vanderstichele C, Jordens P, Deman R, Slabbynck H, et al (2013) Azithromycin for prevention of exacerbations in severe asthma (AZISAST): A multicentre randomised double-blind placebo-controlled trial. Thorax 68: 322-329

34. Walker S, Monteil M, Phelan K, Lasserson TJ, Walters EH. (2006) AntiIgE for chronic asthma in adults and children. Cochrane Database Syst Rev 2006(2):CD003559

35. Rodrigo GJ, Neffen H, Castro-Rodriguez JA (2011) Efficacy and safety of subcutaneous omalizumab vs. placebo as add-on therapy to corticosteroids for children and adults with asthma: A systematic review. Chest 139: 28-35.

36. Pavord ID, Korn S, Howarth P, Bleecker ER, Buhl R, et al. (2012) Mepolizumab for severe eosinophilic asthma (DREAM): A multicentre, double-blind, placebo-controlled trial. Lancet 380: 651-659

37. Nair P, Pizzichini MM, Kjarsgaard M, Inman MD, Efthimiadis A, et al. (2009) Mepolizumab for prednisone-dependent asthma with sputum eosinophilia. N Engl J Med 360: 985-993.
38. Haldar P, Brightling CE, Hargadon B, Gupta S, Monteiro W, et al. (2009) Mepolizumab and exacerbations of refractory eosinophilic asthma. $\mathrm{N}$ Engl J Med 360: 973-984

39. Bel EH, Wenzel SE, Thompson PJ, Prazma CM, Keene ON, et al. (2014) Oral glucocorticoid-sparing effect of mepolizumab in eosinophilic asthma. N Engl J Med 371: 1189-1197.

40. Ortega HG, Liu MC, Pavord ID, Brusselle GG, FitzGerald JM, et al. (2014) Mepolizumab treatment in patients with severe eosinophilic asthma. N Engl J Med 371: 1198-1207.

41. Flood-Page P, Swenson C, Faiferman I, Matthews J, Williams M, et al. (2007) A study to evaluate safety and efficacy of mepolizumab in patients with moderate persistent asthma. Am J Respir Crit Care Med 176: 1062-1071.

42. Flood-Page PT, Menzies-Gow AN, Kay AB, et al. (2003) Eosinophil's role remains uncertain as anti-interleukin- 5 only partially depletes numbers in asthmatic airway. American Journal of Respiratory and Critical Care Medicine 167: 199-204

43. Barnes PJ (1989) Muscarinic autoreceptors in airways. Their possible role in airway disease. Chest 96: 1220-1221.

44. Boterman M, Smits SR, Meurs H, Zaagsma J. (2006) Protein kinase C potentiates homologous desensitization of the beta2-adrenoceptor in bovine tracheal smooth muscle. Eur J Pharmacol 529: 151-156

45. Fardon T, Haggart K, Lee DK, Lipworth BJ (2007) A proof of concept study to evaluate stepping down the dose of fluticasone in combination with salmeterol and tiotropium in severe persistent asthma. Respir Med 101: 1218-1228.

46. Kerstjens HA, Engel M, Dahl R, Paggiaro P, Beck E, et al. (2012) Tiotropium in asthma poorly controlled with standard combination therapy. N Engl J Med 367: 1198-1207.

47. Johnston SL, Martin RJ (2005) Chlamydophila pneumoniae and Mycoplasma pneumoniae. A role in asthma pathogenesis? Am J Respir Crit Care Med 172: 1078-1089.

48. Metz G, Kraft M (2010) Effects of atypical infections with Mycoplasma and Chlamydia on asthma. Immunol Allergy Clin North Am 30: 575-585, vii-viii.

49. Simpson JL, Powell H, Boyle MJ, Scott RJ, Gibson PG (2008) Clarithromycin targets neutrophilic airway inflammation in refractory asthma. Am J Respir Crit Care Med 177: 148-155.

50. Richeldi L, Ferrara G, Fabbri LM, Lasserson TJ, Gibson PG. (2005) Macrolides for chronic asthma. Cochrane Database Syst Rev CD002997

51. Creticos PS, Reed CE, Norman PS, Khoury J, Adkinson NF Jr, et al. (1996) Ragweed immunotherapy in adult asthma. N Engl J Med 334: 501-506.

52. Walker SM, Pajno GB, Lima MT, Wilson DR, Durham SR (2001) Grass pollen immunotherapy for seasonal rhinitis and asthma: A randomized, controlled trial. J Allergy Clin Immunol 107: 87-93.

53. Zielen S, Kardos P, Madonini E (2010) Steroid-sparing effects with allergen-specific immunotherapy in children with asthma: A randomized controlled trial. J Allergy Clin Immunol 126: 942-949.

54. Amin HS, Liss GM, Bernstein DI (2006) Evaluation of near-fatal reactions to allergen immunotherapy injections. J Allergy Clin Immunol 117: 169-175.

55. Massanari M, Nelson H, Casale T, Busse W, Kianifard F, et al. (2010) Effect of pretreatment with omalizumab on the tolerability of specific immunotherapy in allergic asthma. J Allergy Clin Immunol 125: 383-389.

56. Bousquet J, Hejjaoui A, Clauzel AM, Guérin B, Dhivert H, et al. (1988) Specific immunotherapy with a standardized Dermatophagoides pteronyssinus extract. II. Prediction of efficacy of immunotherapy. J Allergy Clin Immunol 82: 971-977

57. Ricci M1 (1994) IL-4: A key cytokine in atopy. Clin Exp Allergy 24: 801-812.

58. Garlisi CG, Kung TT, Wang P, Minnicozzi M, Umland SP, et al. (1999) Effects of chronic anti-interleukin-5 monoclonal antibody treatment in a murine model of pulmonary inflammation. Am J Respir Cell Mol Biol 20: 248-255. 
Citation: Noujeim C, Khalil PB (2016) Severe Asthma: Moving from Phenotype to Endotype Classification with Updates on Treatment. J Nurs

59. Hart TK, Blackburn MN, Brigham-Burke M, Dede K, Al-Mahdi N, et al. (2002) Preclinical efficacy and safety of pascolizumab (SB 240683): A humanized anti-interleukin- 4 antibody with therapeutic potential in asthma. Clin Exp Immunol 130: 93-100.

60. Walker BL, Leigh R (2008) Use of biologicals as immunotherapy in asthma and related diseases. Expert Rev Clin Immunol 4: 743-756.

61. Slager RE, Otulana BA, Hawkins GA, Yen YP, Peters SP, et al. (2012) IL-4 receptor polymorphisms predict reduction in asthma exacerbations during response to an anti-IL-4 receptor an antagonist. J Allergy Clin Immunol 130: 516-522.e4

62. Wenzel S, Ford L, Pearlman D, Spector S, Sher L, et al. (2013) Dupilumab in persistent asthma with elevated eosinophil levels. N Engl J Med 368: 2455-2466.

63. Hua F, Ribbing J, Reinisch W, Cataldi F, Martin S (2015) A pharmacokinetic comparison of anrukinzumab, an anti-IL-13 monoclonal antibody, among healthy volunteers, asthma and ulcerative colitis patients. Br J Clin Pharmacol 80: 101-9

64. Corren J, Lemanske RF, Hanania NA, Korenblat PE, Parsey MV, et al. (2011) Lebrikizumab treatment in adults with asthma. N Engl J Med 365 1088-1098.
65. Hanania NA, Noonan M, Corren J, Korenblat P, Zheng Y, et al. (2015) Lebrikizumab in moderate-to-severe asthma: Pooled data from two randomised placebo-controlled studies. Thorax 70: 748-756.

66. Hanania NA, Korenblat P, Chapman KR, Bateman ED, Kopecky P, et al. (2016) Efficacy and safety of lebrikizumab in patients with uncontrolled asthma (LAVOLTA I and LAVOLTA II): Replicate, phase 3, randomised, double-blind, placebo-controlled trials. Lancet Respir Med 4: 781-796

67. Piper E, Brightling C, Niven R, Oh C, Faggioni R, et al. (2013) A phase II placebo-controlled study of tralokinumab in moderate-to-severe asthma. Eur Respir J 41: 330-338.

68. Brightling CE, Chanez P, Leigh R, O'Byrne PM, Korn S, et al. (2015) Efficacy and safety of tralokinumab in patients with severe uncontrolled asthma: a randomised, double-blind, placebo-controlled, phase $2 \mathrm{~b}$ trial. Lancet Respir Med 3: 692-701

69. Wheelock CE, Goss VM, Balgoma D, Nicholas B, Brandsma J, et al. (2013) Application of omics technologies to biomarker discovery in inflammatory lung diseases. Eur Respir J 42: 802-825. 